\title{
Azithromycin induces epidermal differentiation and multivesicular bodies in airway epithelia
}

Ari Jon Arason ${ }^{1,6 \dagger}$, Jon Petur Joelsson ${ }^{1 \dagger}$, Bryndis Valdimarsdottir ${ }^{1,6}$, Snaevar Sigurdsson ${ }^{1}$, Alexander Gudjonsson ${ }^{1}$, Skarphedinn Halldorsson², Freyr Johannsson ${ }^{2}$, Ottar Rolfsson², Fredrik Lehmann ${ }^{6}$, Saevar Ingthorsson ${ }^{1,6}$, Paulina Cherek ${ }^{4}$, Gudmundur H. Gudmundsson ${ }^{5}$, Fridrik R. Gardarsson ${ }^{6}$, Clive P. Page ${ }^{6,8}$, Olafur Baldursson ${ }^{6,7}$, Thorarinn Gudjonsson ${ }^{1,3,6}$ and Jennifer A. Kricker ${ }^{1,6^{*}}$ (D)

\begin{abstract}
Background: Azithromycin (Azm) is a macrolide recognized for its disease-modifying effects and reduction in exacerbation of chronic airway diseases. It is not clear whether the beneficial effects of Azm are due to its anti-microbial activity or other pharmacological actions. We have shown that Azm affects the integrity of the bronchial epithelial barrier measured by increased transepithelial electrical resistance. To better understand these effects of Azm on bronchial epithelia we have investigated global changes in gene expression.

Methods: VA10 bronchial epithelial cells were treated with Azm and cultivated in air-liquid interface conditions for up to 22 days. RNA was isolated at days 4, 10 and 22 and analyzed using high-throughput RNA sequencing. qPCR and immunostaining were used to confirm key findings from bioinformatic analyses. Detailed assessment of cellular changes was done using microscopy, followed by characterization of the lipidomic profiles of the multivesicular bodies present.
\end{abstract}

Results: Bioinformatic analysis revealed that after 10 days of treatment genes encoding effectors of sterol and cholesterol metabolism were prominent. Interestingly, expression of genes associated with epidermal barrier differentiation, KRT1, CRNN, SPINK5 and DSG1, increased significantly at day 22. Together with immunostaining, these results suggest an epidermal differentiation pattern. We also found that Azm induced the formation of multivesicular and lamellar bodies in two different airway epithelial cell lines. Lipidomic analysis revealed that Azm was entrapped in multivesicular bodies linked to different types of lipids, most notably palmitate and stearate. Furthermore, targeted analysis of lipid species showed accumulation of phosphatidylcholines, as well as ceramide derivatives.

Conclusions: Taken together, we demonstrate how Azm might confer its barrier enhancing effects, via activation of epidermal characteristics and changes to intracellular lipid dynamics. These effects of Azm could explain the unexpected clinical benefit observed during Azm-treatment of patients with various lung diseases affecting barrier function.

Keywords: Azithromycin, Air-liquid interface, Gene expression, Airway, Epithelia, Epidermal differentiation

\footnotetext{
* Correspondence: jenk@hi.is

${ }^{\dagger}$ Ari Jon Arason and Jon Petur Joelsson are co-first authors

${ }^{1}$ Stem Cell Research Unit, BioMedical Center, School of Health Sciences,

University of Iceland, Reykjavík, Iceland

${ }^{6}$ EpiEndo Pharmaceuticals, Reykjavík, Iceland

Full list of author information is available at the end of the article
}

(c) The Author(s). 2019 Open Access This article is distributed under the terms of the Creative Commons Attribution 4.0 International License (http://creativecommons.org/licenses/by/4.0/), which permits unrestricted use, distribution, and reproduction in any medium, provided you give appropriate credit to the original author(s) and the source, provide a link to the Creative Commons license, and indicate if changes were made. The Creative Commons Public Domain Dedication waiver (http://creativecommons.org/publicdomain/zero/1.0/) applies to the data made available in this article, unless otherwise stated. 


\section{Background}

The global burden of chronic lung diseases has been demonstrated in various epidemiological studies. Patients with lung diseases including COPD, asthma, diffuse panbronchiolitis and cystic fibrosis (CF) are often admitted to hospitals with acute exacerbations [1]. These admissions can be due to underlying bacterial infections for which the first line of treatment includes macrolide antibiotics [2-8]. Patients that receive macrolide therapy show improved prognosis with fewer and less severe acute exacerbations resulting in fewer hospital admissions [8-11]. These beneficial effects appear to be independent of bactericidal activity [12] and are particularly shown to improve health in patients with COPD regardless of the status of the airway bacterial infections, including that of $P$. aeruginosa colonization $[2,13,14]$.

Macrolides are compounds whose chemical structure includes a macrolactone ring backbone. The first identified macrolide was the 14-membered erythromycin. [15, 16]. Azithromycin (Azm), a 15-membered macrolide derived from erythromycin [17], is one of the most prescribed antibiotics in the U.S. [18] and is known to have additional effects aside from its primary role as an antibiotic. Metaanalysis of patients receiving Azm for treatment of chronic airway diseases reveals that many of these patients have fewer acute exacerbations that require hospital admissions. Traditionally macrolides are said to be anti-inflammatory and capable of modulating inflammatory responses, in addition to their bactericidal effect [19]. However, this hypothesis is debated, and the pharmacological activities that explain the observed clinical benefit of Azm remain unproven. Indeed, a recent clinical study reported that Azm reduced exacerbations when administered for 48 weeks to patients with asthma. Interestingly, sputum samples neither indicated significant anti-microbial activity, nor changes in the number of inflammatory cells [20].

Complementing these findings, it has been shown that Azm enhances epithelial barrier function of bronchial epithelial cells when cultivated under air-liquid interface (ALI) conditions [21]. Azm increased the transepithelial electrical resistance (TEER) of VA10, a bronchial epithelial cell line, in ALI culture, while also affecting the processing of tight junction proteins. Moreover, epithelial integrity was maintained during exposure of airway epithelia to $P$. aeruginosa infection [22]. In another study by Slater et al. [23], it was demonstrated that Azm increased TEER in human primary bronchial epithelial cells in ALI culture upon challenge with lipopolysaccharides derived from $P$. aeruginosa. They showed that Azm increased the thickness of the epithelium, reduced the mucin production and resulted in a decrease in metalloprotease (MMP9) production. Collectively the data illustrate that AZM has a barrier effect. Further understanding of this unusual and off target effect of Azm is important and could produce novel strategies to combat barrier failure.
Based upon several previous studies we hypothesized that the effect of Azm was primarily on airway epithelial cells. Therefore, we investigated the effects of Azm on epithelial gene expression and found that Azm had pronounced temporal effects on bronchial epithelial cells grown in ALI culture. Gene sequencing analysis demonstrated increasing differentiation towards an epidermal phenotype with upregulation of several skin associated markers. This was accompanied by the formation of multivesicular and lamellar bodies that may be one of the factors that contribute to the barrier enhancing effects of Azm. Exploring further the barrier enhancing effects of Azm is of importance as barrier failure in the respiratory system can contribute to a wide range of disease conditions and exacerbation of chronic airway diseases.

\section{Material and methods \\ Cell culture}

VA10 [24] and BCi-NS1.1 [25] (Cornell University Licensing Agreement) cells lines were cultured in BEGM medium supplemented with retinoic acid, penicillin (50 $\mathrm{IU} / \mathrm{mL})$ and streptomycin $(50 \mu \mathrm{g} / \mathrm{mL})$ (Invitrogen). VA10 cells were used between passages 11-20, and BCi-NS1.1 cells between passages 11-24. Both cell lines were maintained in a humidified incubator at $37^{\circ} \mathrm{C}$ and $5 \% \mathrm{CO}_{2}$. Medium was changed every 2 to 3 days.

\section{Air-liquid interface culture}

Air-liquid interface (ALI) culture was conducted using both VA10 and BCi-NS1.1 cells. Transwell filter inserts (Corning $0.4 \mu \mathrm{M}$ PET membrane) were pre-coated with human type IV collagen (Sigma), and cells were trypsinized and seeded in 50:50 DMEM/Ham's F-12 containing 10\% FBS (ThermoFisher). $2.0 \times 10^{5}$ cells $/ \mathrm{cm}^{2}$ and $4.5 \times 10^{5}$ cells $/ \mathrm{cm}^{2}$ of VA10 and BCi-NS1.1, respectively, were seeded in $0.5 \mathrm{~mL}$ on the apical side of the insert, and $1.5 \mathrm{~mL}$ medium added to the basolateral chamber. After 1 day, the medium in both chambers was changed to DMEM/Ham's F-12 containing 2\% Ultroser G (Pall Scientific). After 2 days when the cell layer was confluent, medium was removed from the apical chamber to create an air-interface, and treatments commenced. Typically, treatments were for either 2 or 3 weeks, and medium was changed every 2-3 days. Azm used was Zithromax ${ }^{\oplus}$ (Pfizer, NY, USA) $(53.4 \mu \mathrm{M})$ and from Sigma (Missouri, USA) (31.8 $\mu \mathrm{M})$. All experiments were done in technical triplicates, as well as biological replicates.

\section{Paracellular flux assay and TEER}

VA10 cells were grown in ALI culture and sodium fluorescein (Sigma) permeation was performed at different time points to determine the paracellular flux from the apical to basolateral compartments. ALI cultures were equilibrated for $30 \mathrm{~min}$ in Hanks' Balanced Salt Solution (Gibco HBSS). Sodium fluorescein in HBSS $(50 \mu \mathrm{M})$ was added to 
the apical chamber, with $1.5 \mathrm{~mL}$ of HBSS in the basolateral chamber. Sampling from the basolateral compartment was done after 20, 40, 60, 80 and $120 \mathrm{~min}$ and HBSS volume replenished each time.

TEER was measured before and after the experiment to ensure barrier integrity.

\section{RNA sequencing and gene expression analysis}

RNA was extracted from cells grown in ALI culture and poly-A mRNA libraries were prepared for deep sequencing analysis using an Illumina HiSeq 2500. Triplicate samples were prepared and sequenced from Azm treated cells and untreated cells at days 4, 10 and 22 .

The Kallisto (v 0.43) program [26, 27] was utilized for the measurement of differential expression and to obtain $q$ values for each transcript. For enrichment analysis we selected transcripts with differential expression in Azm treated cells versus untreated cells based on Kallisto/ sleuth q-values, and with at least two-fold increases in expression (beta $>0.63$ ). The top differently expressed transcripts based on q-values $(\mathrm{q}<0.01)$ (for day 22: 1000 upregulated transcripts and bottom 500 downregulated transcripts) were analyzed with the Panther classification system for GO biological processes (The PANTHER (protein annotation through evolutionary relationship) classification system (version 183), released on 12 September, 2018; http://www.pantherdb.org/) [28] to identify biological processes up or down regulated in the Azm treated cells (Overrepresentation Test).

\section{qRT-PCR}

Total RNA was extracted with Tri-Reagent (Ambion, ThermoFisher). One $\mu \mathrm{g}$ of RNA was reverse transcribed with hexanucleotide primers using Superscript IV (ThermoFisher). Resulting cDNA was used as template for qPCR. Primer pairs and probes from Applied Biosystems (TaqMan) were used for CRNN (Hs.PT.58.45584843), DSG1 (Hs.PT.58.19323131), KRT1 (Hs.PT.58.24741966), SPINK5 (Hs.PT.58.27676526), and PPIA (Hs.PT.39a.22214851) or GAPDH (Hs.PT.39a.22214836) as endogenous reference genes. Gene expression is performed in triplicate technical replicates, as well as biological replicates.

\section{Immunostaining}

Samples were fixed in formalin and embedded in paraffin before being sectioned and immunostained. Three $\mu \mathrm{m}$ thick slides were incubated at $60^{\circ} \mathrm{C}$ for an hour prior to staining. Before staining, the sample antigen retrieval was done in a buffer with either citric buffer (pH 6) or TE buffer (pH 9) for $20 \mathrm{~min}$. Samples were then blocked with serum. The primary antibody was incubated overnight at $4{ }^{\circ} \mathrm{C}$ and the secondary antibody incubated at room temperature for $30 \mathrm{~min}$. Secondary antibodies used included Dako EnVision+ system-HRP labelled polymer anti-mouse (K400011-
2), anti-rabbit (K400211-2) and the DAB substrate kit (ab94665). A kit containing DAB chromogen and substrate buffer (ab94665) was used according to the manufacturer's instructions.

\section{Microscopy}

Immunofluorescence was visualized and captured using an Olympus FV1200 Confocal microscope (Olympus, Tokyo, Japan). Bright-field and phase-contrast images of samples were captured using an EVOS FL Auto 2 imaging system (ThermoFisher).

\section{Transmission electron microscopy}

VA10 and BCi-NS1.1 cells were grown as monolayers on coverslips and under ALI conditions, and prepared for electron microscopy. Cells were fixed with $2.5 \%$ glutaraldehyde for $20 \mathrm{~min}$. Fixed coverslips/filters were placed in $2 \%$ osmium tetroxide, followed by a phosphate buffer rinse. Cells were dehydrated and then embedded in resin. $100 \mathrm{~nm}$ sections were cut with an Ultramicrotome (Leica EM UC7). Sections were stained with lead citrate (3\%, J.T. Baker Chemical Co.) and imaged using a JEM-1400PLUS PL Transmission Electron Microscope.

\section{LipidTOX assay}

Cells were grown with and without treatment of Azm $(53.4 \mu \mathrm{M})$ for 5 days. The cells were then seeded into 96 well plates containing $1 \mathrm{X}$ LipidTOX ${ }^{\mathrm{m} x}$ phospholipidosis detection reagent (ThermoFisher) and incubated for 72 $\mathrm{h}$ and live cell imaged using an FV1200 Olympus Inverted Confocal Microscope. Quantification of fluorescence intensity was measured using ImageJ. A total of three biological repeats were done $(n=3)$.

\section{Lipidomic analysis}

Lipids were extracted from cell cultures by liquid-liquid extraction. Thawed cell pellets were resuspended in icecold methanol, vortexed vigorously and allowed to stand on ice for $10 \mathrm{~min}$. Equal amounts of water and chloroform were added to a final composition of 1:1:1 $\left(\mathrm{CH}_{3} \mathrm{OH}: \mathrm{H}_{2} \mathrm{O}\right.$ : $\mathrm{CHCl}_{3}$ ), vortexed and left to stand overnight at $4{ }^{\circ} \mathrm{C}$. The organic phase was collected into a glass vial and solvent evaporated in a miVac concentrator (SP scientific, Warminster PA, USA) and reconstituted 2-propranol:ACN: $\mathrm{H}_{2} \mathrm{O}(2: 1: 1, \mathrm{v} / \mathrm{v} / \mathrm{v})$ for analysis.

Lipidomic analysis was performed using ultra performance liquid chromatography (UPLC, ACQUITY, Waters, Manchester, UK) coupled with a quadrupole time-of-flight mass spectrometry (Synapt G2, Waters, Manchester, UK) operating in $\mathrm{MS}^{\mathrm{E}}$ mode with ion mobility separation. Samples were injected onto a $1.7 \mu \mathrm{m}$ particle $100 \times 2.1$ mm CHS C18 column (ACQUITY, Waters, Manchester, UK). Mobile phase A was water/acetonitrile 80:20 (v/v) containing $0.05 \%$ formic acid and $5 \mathrm{mM}$ ammonium 
formate, mobile phase B was 2-propanol/acetonitrile 90:10 (v/v) containing $0.05 \%$ formic acid and $5 \mathrm{mM}$ ammonium formate. Data acquisition took place over the mass range of 150-1100 Da with two alternating scan modes: a low energy mode with the collision energy in the trap cell set at $6 \mathrm{eV}$, and a high energy mode with the collision energy in the trap cell set at $6 \mathrm{eV}$ and a collision energy ramp ranging from 20 to $30 \mathrm{eV}$ in the transfer cell. In both scan modes the scan time was $0.5 \mathrm{~s}$. Data processing and analysis were performed with MassLynx v4.1 (Waters), Targetlynx v4.1 (Waters) and Driftscope v2.8 (Waters). Statistical analysis was performed with Metaboanalyst as previously described [29].

\section{Statistical analysis}

All growth curves were performed in triplicate for statistical accuracy. Graphs were created in GraphPad Prism. Statistical significance was determined using Student's t-tests. Error bars represent the standard deviation (SD) of the sample.

\section{Results}

Azm treatment of human bronchial epithelial cells increases transepithelial resistance and reduces paracellular flux

We first sought to confirm the effect of Azm on bronchial epithelial cells from previous studies. Cells were grown in ALI conditions for 3 weeks and TEER and paracellular flux were measured. Here, we show that both the VA10 and the bronchial-derived basal cell line BCi-NS1.1 [25] demonstrate an inverse relationship between TEER and paracellular flux after treatment with Azm. After approximately 1 week of Azm treatment, TEER begins to increase as compared to non-treated controls (Fig. 1a). Conversely, as TEER increases, paracellular flux decreases (Fig. 1b). In monolayer culture, the VA10 cell line shows a P63/Cytokeratin 14 positive basal epithelial phenotype [30] and thus, the ALI cultures can be considered "naïve" at day 0 . To examine if Azm treatment resulted in histology alterations in the ALI cultures, ALI filters were embedded in paraffin and cross-sectioned for microscopic analysis. We observed a thickening of the epithelial layer and the formation of large intracellular vesicles with Azm treatment (Fig. 1c).

\section{Azm treatment of bronchial epithelial cells results in global and temporal changes in gene expression}

In order to investigate the scope of gene expression changes associated with the cellular observations after Azm treatment in VA10 cells during ALI culture, RNA sequencing was performed on samples collected at three time points during culture: day 4,10 and 22 . The time points selected reflect various stages of differentiation as indicated by rising TEER and reduced paracellular flux. This extended duration of treatment from 2 weeks to 3 weeks was based on reports stating that long term Azm treatment is beneficial for patients with chronic airway diseases [4, 31]. Gene expression analysis revealed global changes throughout the culture period. To assist in interpreting these data, we used the PANTHER gene ontology (GO) classification system [32] to identify striking patterns in the development of increased epithelial barrier function. At day 4, only a few gene transcripts (36) were upregulated according to our statistical criteria (q-value less than 0.01 and more than 2-fold upregulation). However, at day 10, the expression profile was enriched in genes associated with sterol/cholesterol metabolism, an important component of epidermal barrier formation (Table 1) [33-35]. Interestingly, after 22 days of treatment, an overexpression profile in the domain of epidermal ontology groups was enriched. This included keratinization, cornification, keratinocyte differentiation, and establishment of skin barrier regulation of water loss via skin and desmosome organization. The 20 most upregulated genes and their assigned gene ontology groups at the last time point were analyzed and a strong epidermal barrier fingerprint was evident (Table 2). Of particular interest we saw a significant upregulation of NDRG1, which recently was directly associated with positive effects on airway epithelial barrier strengthening [36]. We then set out to depict the differential expression pattern of gene transcripts within these categories during Azm treatment and included transcripts known to be active in the formation of the skin barrier related to corneocyte lipid envelope and the epidermal differentiation complex (EDC). The EDC is a complex consisting of proteins encoded by 51 genes involved in the terminal differentiation and cornification of keratinocytes, spanning a $1.9 \mathrm{Mb}$ stretch within chromosome 1q21. After 4 days of treatment, there was very little effect on expression within these categories. After 10 days there was low to intermediate upregulation, while after 22 days a clear upregulation pattern was distinct (Fig. 2a-e). Since transcripts can be classified into more than one $\mathrm{GO}$ group, we utilized a recent publication to increase our confidence that these upregulating effects were truly epidermal related. Gerber et al. [37] revealed 687 genes as being specifically skin associated genes (SAG) and assigned them to a total of 15 functional groups. Our results revealed that of the statistically upregulated genes induced by Azm treatment on day 22, $40.3 \%$ pertained to the SAG group, in contrast to $14.8 \%$ of an equally numbered list of genes that were randomly generated. Interestingly, one of the three most represented functions was vesicle formation.

Expression of a selection of genes from each of the GO groups was confirmed using qRT-PCR (Fig. 3a). Genes showing significant increase after Azm treatment included: Cytokeratin 1 (KRT1), that acts together with keratin 10 to form intermediate filaments to provide strength, albeit most notably in skin; Cornulin (CRNN), also known as squamous epithelium shock protein 53 that 


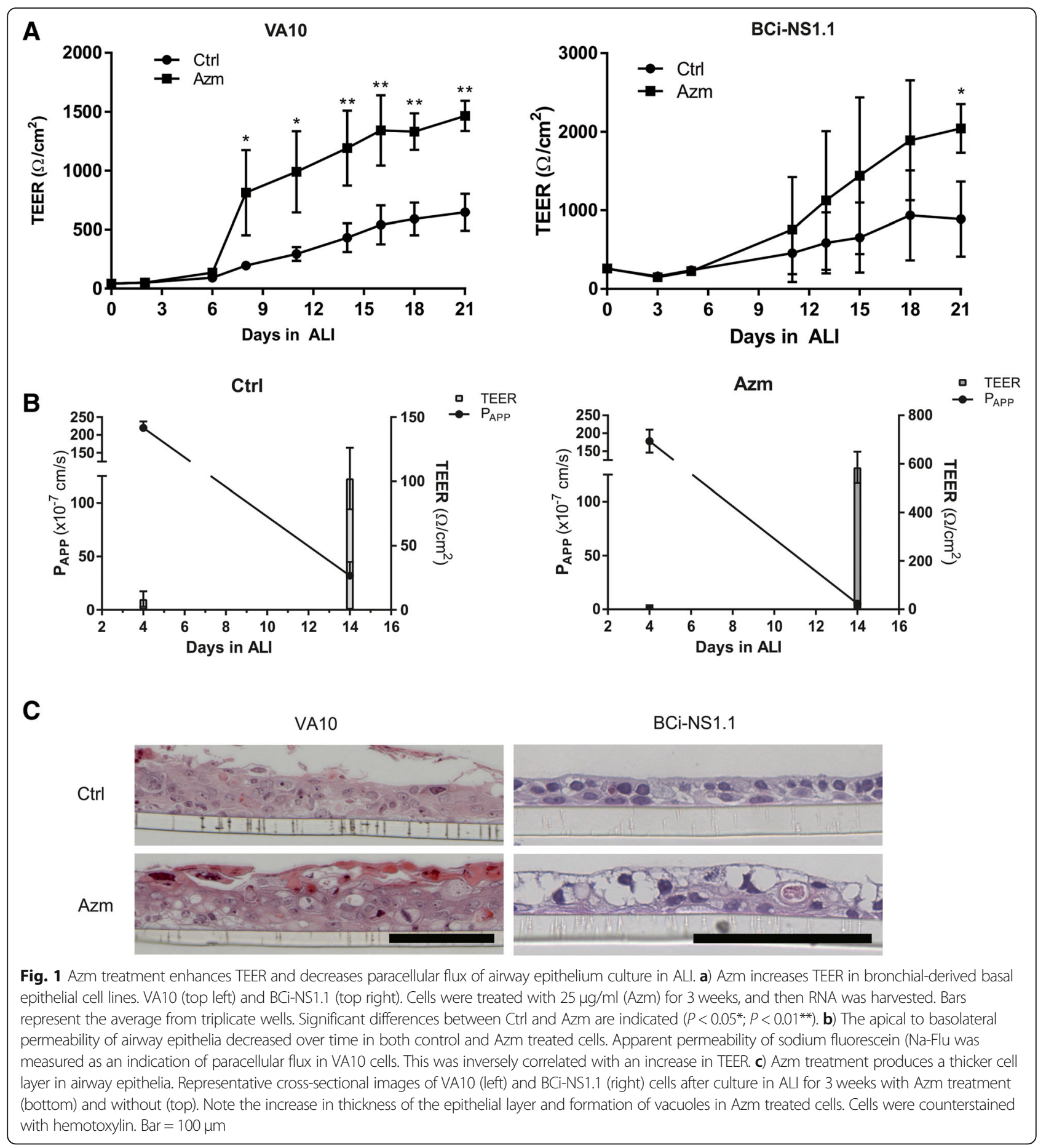

is suggested to play a role in the mucosal/epithelial immune response and epidermal differentiation; and desmoglein 1 (DSG1), a major component of desmosome cell-cell junctions. Additionally, we also observed changes in the serine protease inhibitor Kazal-inhibitor 5 (SPINK5), which is known to regulate proteases and be involved in respiratory processes. To assess any alterations in the tissue architecture, cross-sections of
ALI cultures from day 22 were examined (Fig. 3b). Notably, the Azm treated cultures were thicker and vesicle formations were apparent. ALI cultures treated for 3 weeks with Azm were stained for markers with increased gene expression. Again, staining of epidermal barrier associated proteins revealed dramatic increase in expression of cytokeratin 1 and corneodesmosin, with notable de novo apical expression of the latter. 


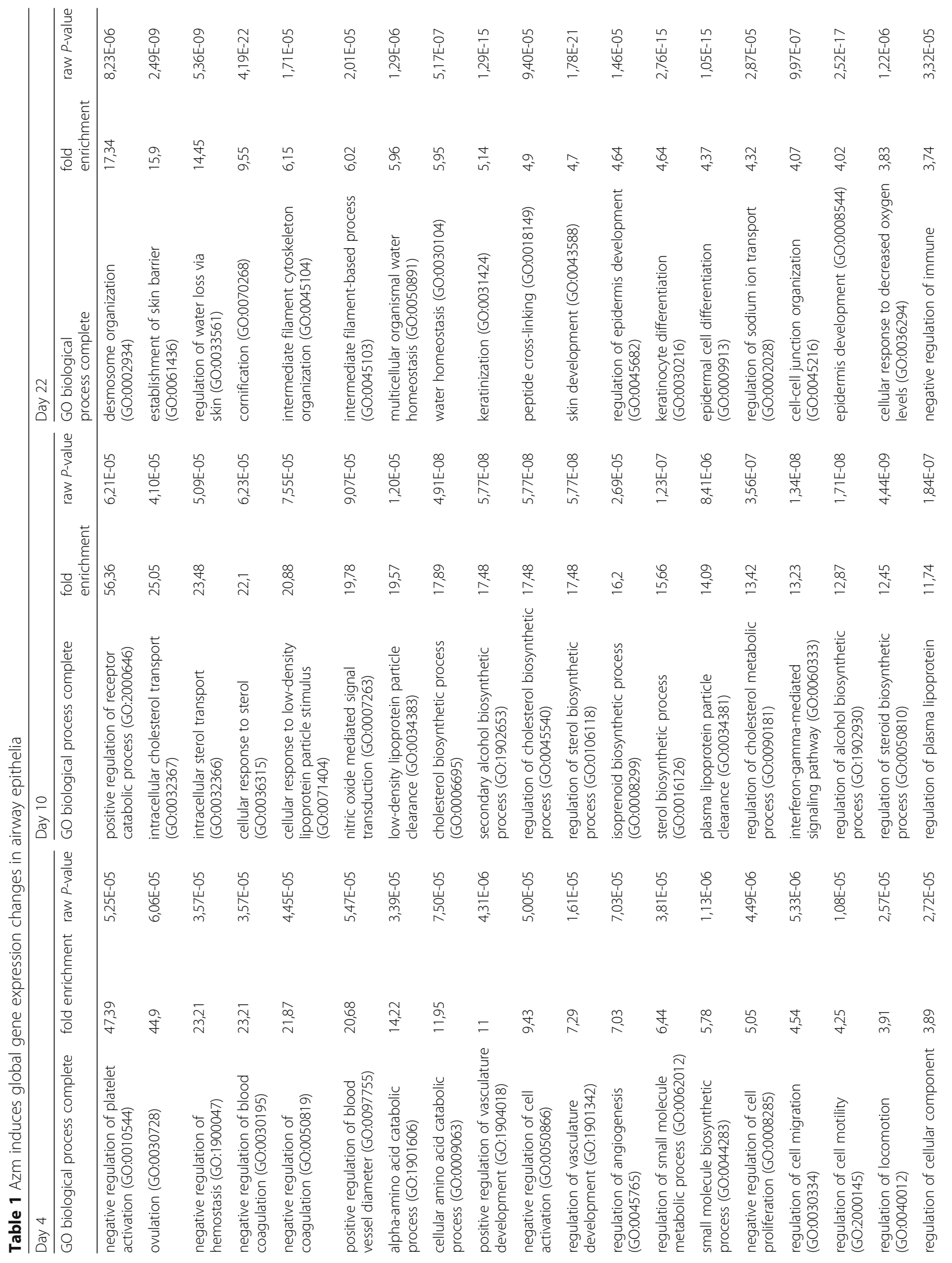




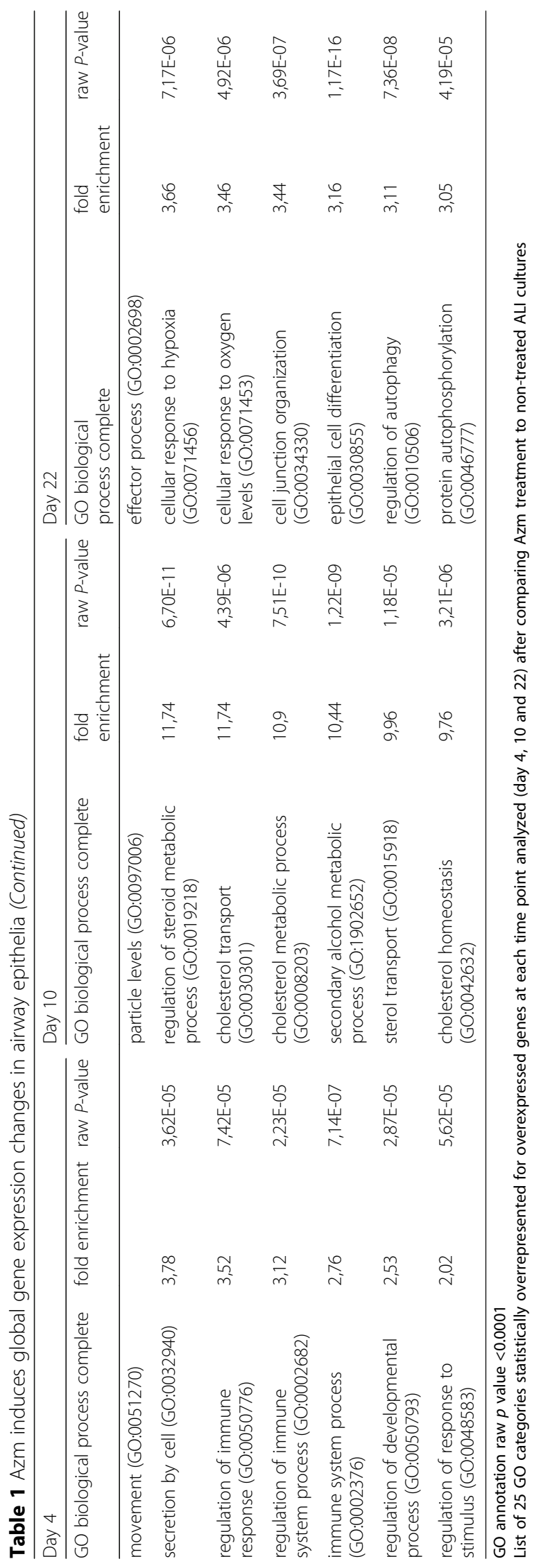




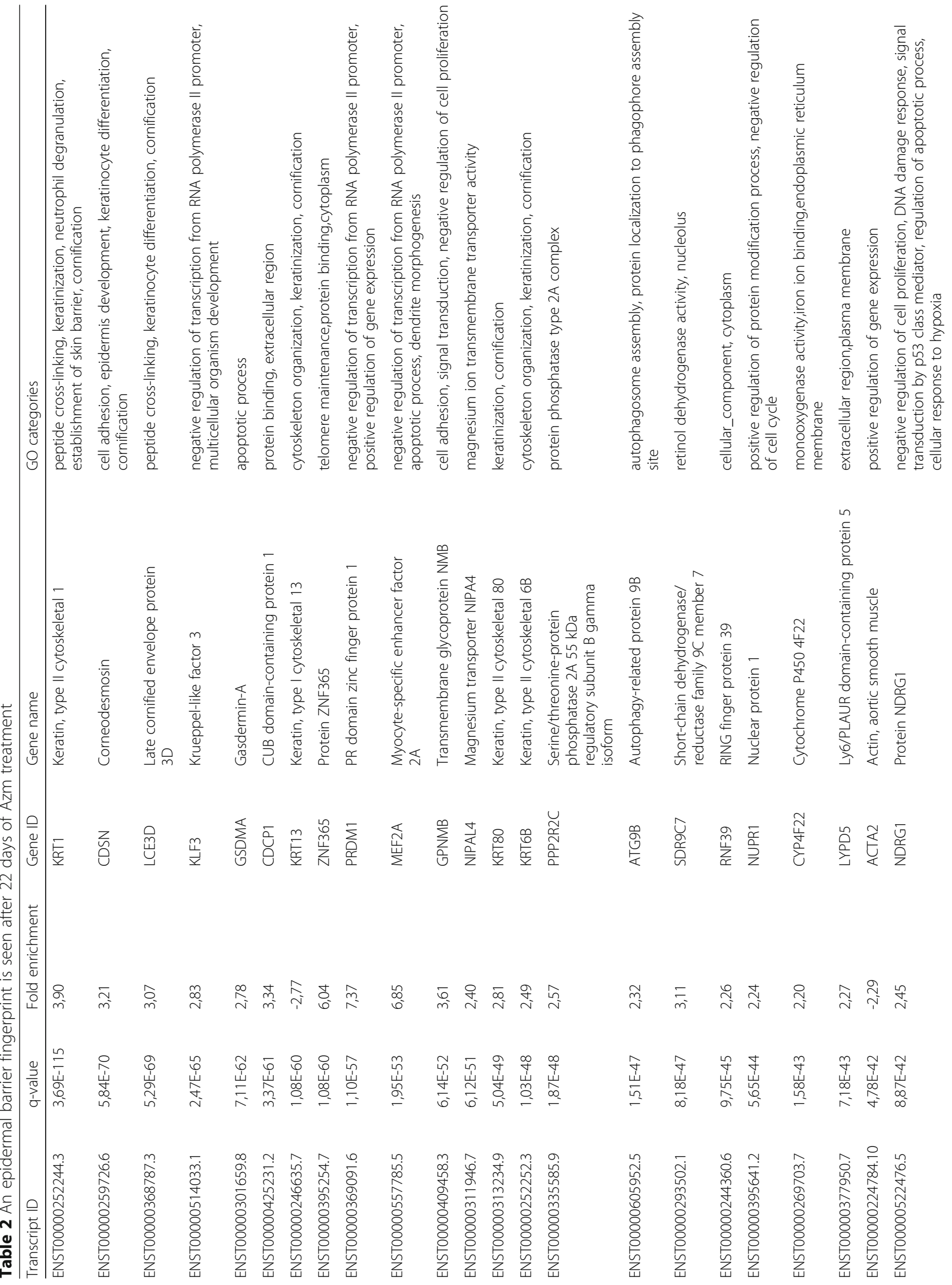




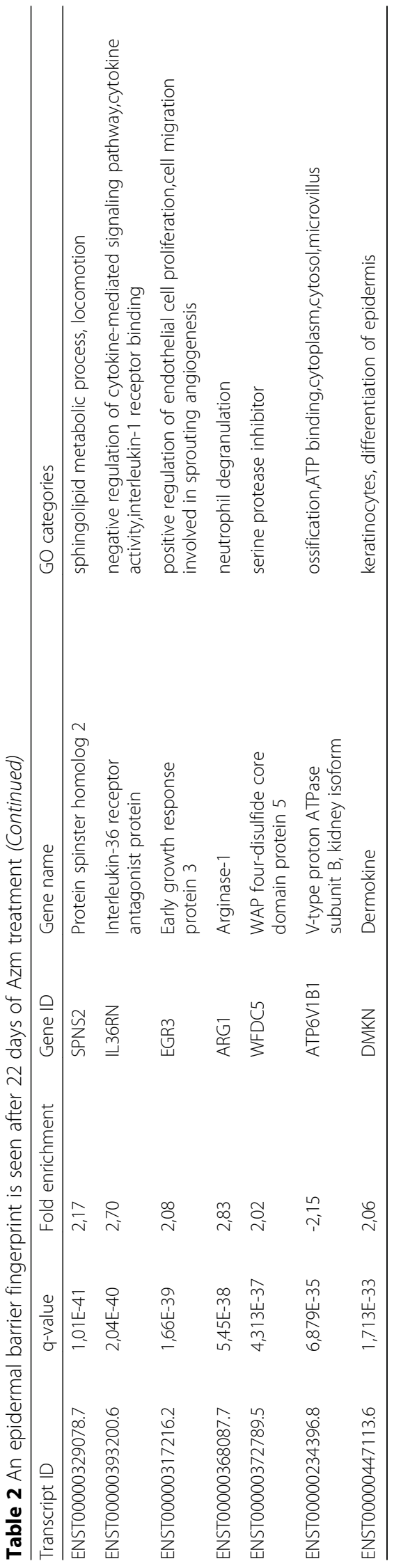



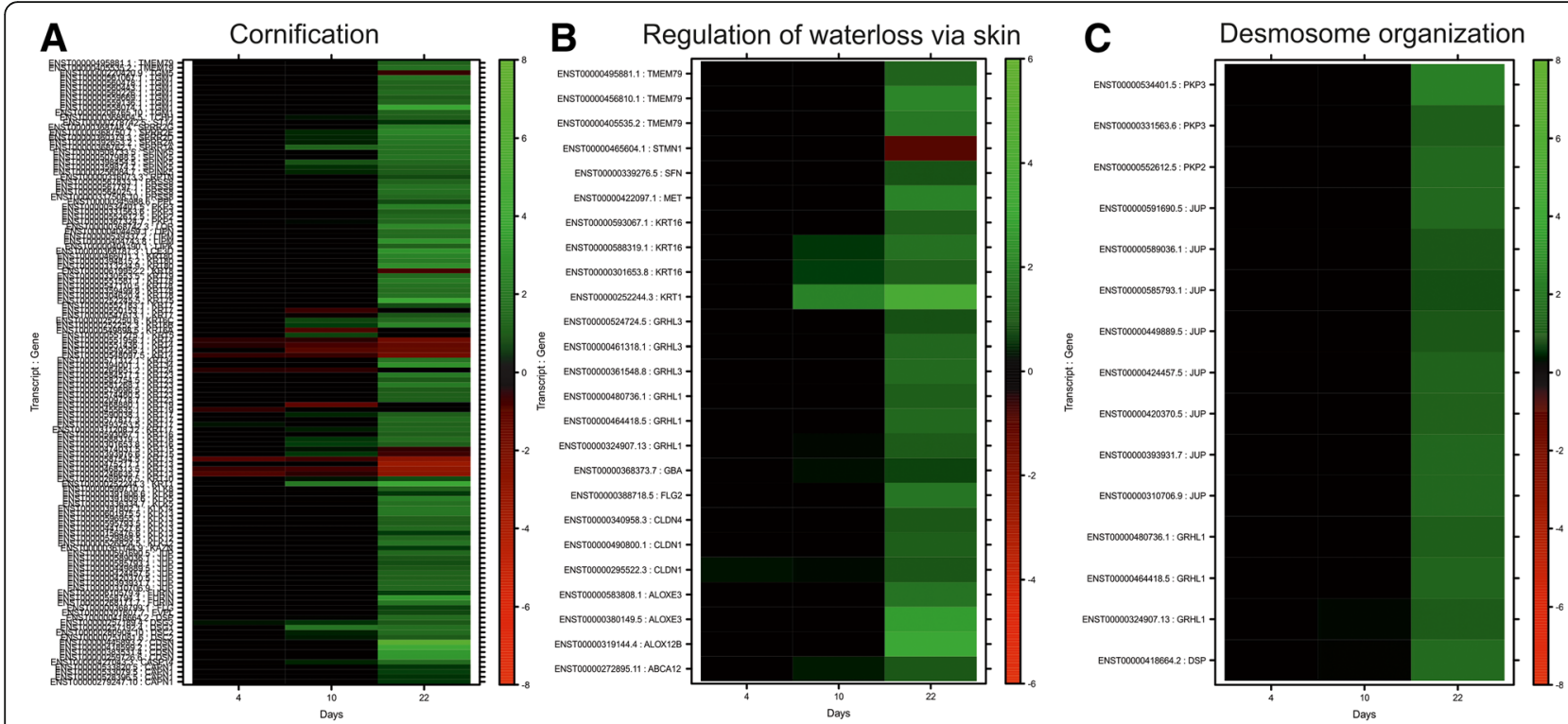

\section{Epidermal differentiation complex}
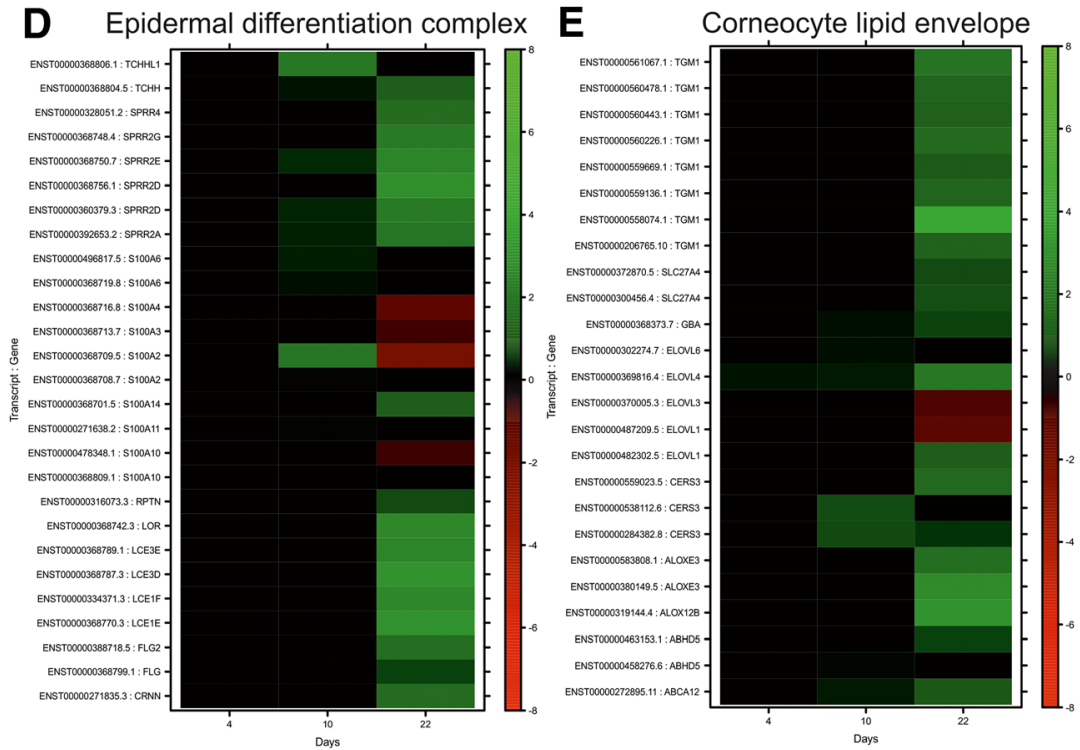

Fig. 2 Heatmaps showing upregulated genes involved in late epidermal differentiation and barrier formation as a result of Azm treatment of airway epithelia. Analysis of RNA sequencing of VA10 cells after 4, 10 and 22 days of treatment of Azm in ALI culture. Sequencing was done on triplicate samples. Heatmap showing hierarchically clustered log2(ratio) data, where the ratio is defined as mRNA expression level in control cells to Azm-treated cells. Data are shown for genes differentially expressed at one or more of the three time points during differentiation. Heatmaps showing up/downregulation of transcripts arranged in gene ontology (GO)-groups involved, including (a) cornification, (b) regulation of water loss via skin, (c) desmosomal organization, (d) epidermal differentiation complex (EDC), (e) corneocyte lipid envelope (CLE). Green color represents increased gene expression relative to red color representing decreased expression

The tight junction protein claudin 1 along with desmoplakin and desmoglein 2 were also expressed (Fig. 3b).

\section{Azm treatment induces accumulation of intracellular vesicles containing phospholipids}

To further characterize the vesicle formation following Azm treatment, we performed transmission electron microscopy imaging on airway epithelia grown in monolayer. Both VA10 and BCi-NS1.1 cells treated with Azm for 5 days showed a clear increase in vesicle formation and many of these vesicles were phenotypically identified as multivesicular bodies (MVB) (Fig. 4a and Additional file 1: Figure S1). These vesicles were shown to accompany lipid accumulation as highlighted by a lipidTOX assay, whereby 


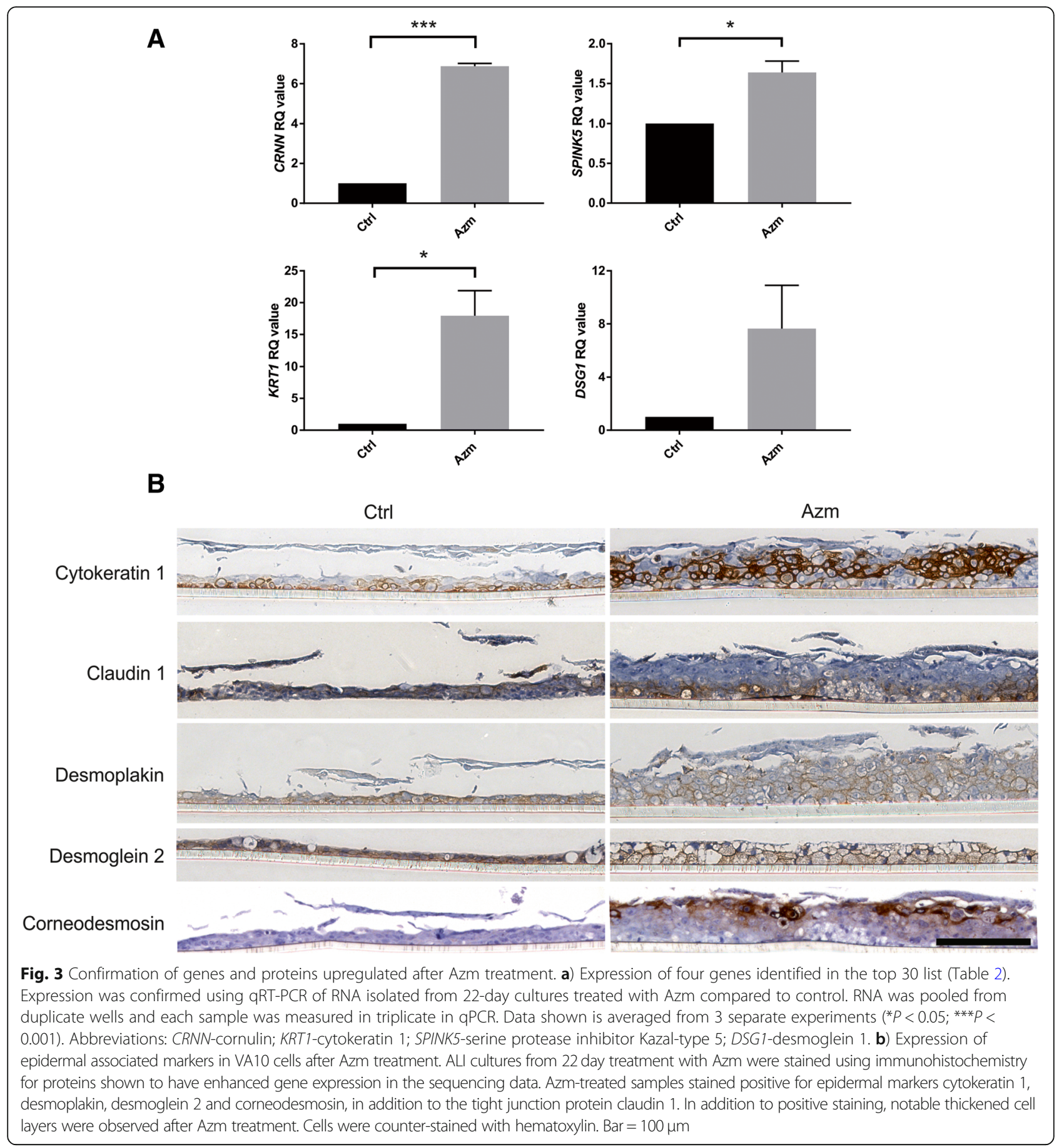

phospholipids conjugated to a fluorescent dye are added to the culture media (Fig. 4b). The Azm treated cells showed a significant $(P<0.01)$ increase in lipid retention when compared to the control (Fig. 4c).

\section{Formation of multivesicular- and lamellar- bodies with Azm treatment in ALI cultures}

Combining the data from the epidermal GO groups and the lipid-containing vesicles after Azm treatment raised the question as to whether the MVB identified in Fig. 4a mature into lamellar bodies (LB). Cells cultured in ALI conditions and treated with Azm showed the same MVB formations as the Azm treated monolayer cells as seen in cross sectional electron microscope images (Fig. 5a). LB formations were observed in these cell layers. This was not seen in any of the ALI cultured control cells (Fig. 5a and Additional file 2: Figure S2A). LB formations were also prevalent in ALI cultured cells treated with a clinical formulation of Azm (Zithromax) 

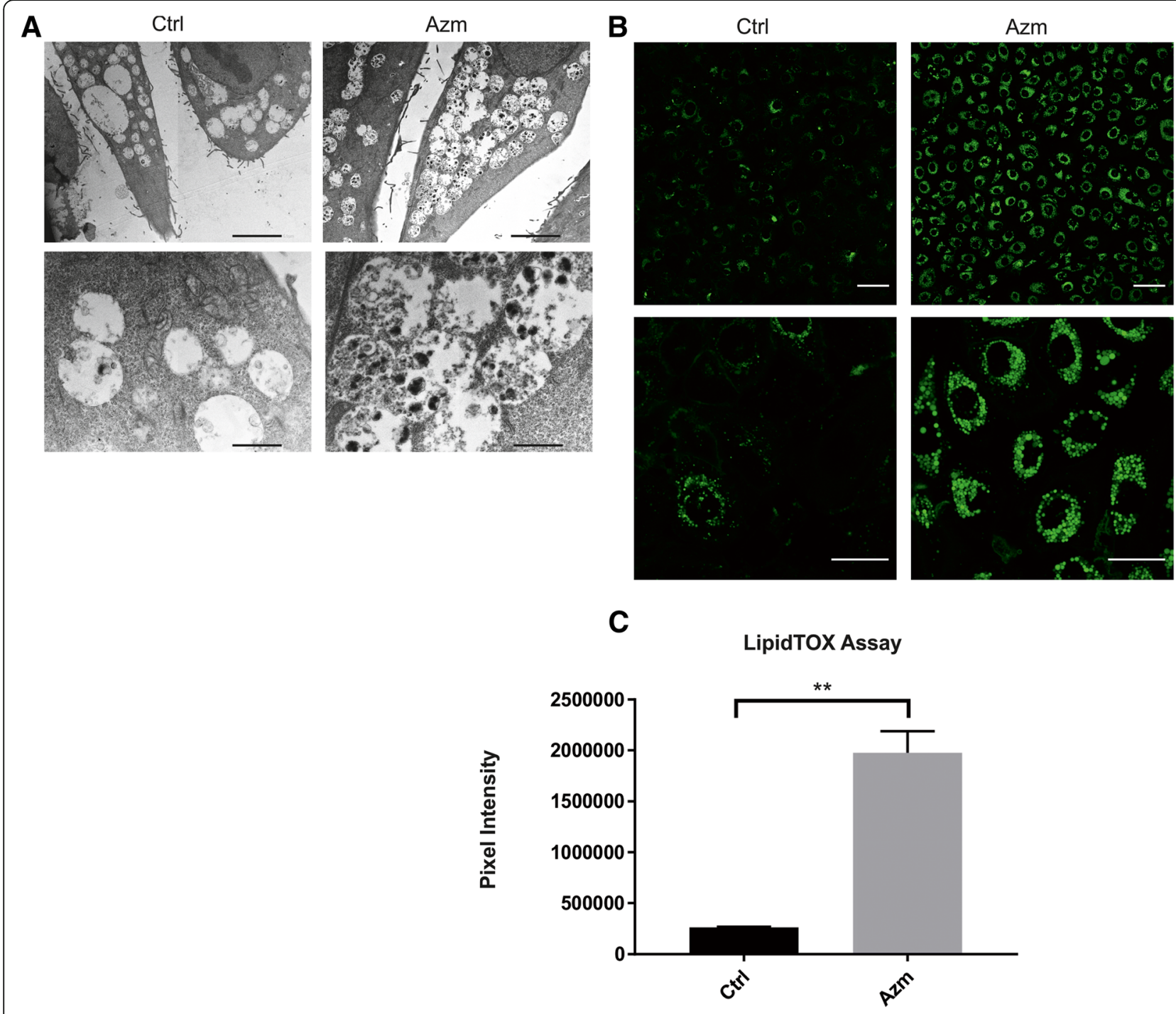

Fig. 4 Increased vesicle formation and lipid retention in Azm treated airway epithelial monolayer. a. Transmission electron microscope images showing that airway epithelia grown in monolayer (VA10 cells) treated with Azm have substantially more vesicle formation than the controls. Many of these vesicles were identified phenotypically as multivesicular bodies (MVB). Top scale bars are $5.0 \mu \mathrm{m}$ and bottom scale bars are $1.0 \mu \mathrm{m}$. b. Increased lipid retention in Azm-treated VA10 cells seeded with HCS LipidTOX reagent. Representative images from 3 biological replicates. Top scale bar is $40 \mu \mathrm{m}$ and bottom scale bars are $20 \mu \mathrm{m}$. c. Quantification of LipidTOX retention from confocal microscopy images in Fig. $4 \mathrm{~b}$. The mean pixel intensity of different wells from 3 different experiments was calculated using ImageJ $(P<0.01)$

(Additional file 2: Figure S2B). This was not limited to VA10 cells, as the BCi-NS1.1 cell line displayed similar MVB and LB formation after Azm (Zithromax) treatment (Additional file 2: Figure S2C). Figure 5b (adapted from [38]) summarizes the formation of MVB and LB. Western blot analysis for known markers related to LBs revealed an increased expression in LAMP1 (lysosome-associated membrane glycoprotein 1) [39] in Azm treated cells, while pro-surfactant protein B (Pro-SFPB) did not (Fig. 5c).

\section{Lipid-Azm conjugates accumulate inside cells}

To further analyze the lipid retention of the Azm treated cells, non-polar metabolites were extracted from VA10 and BCi-NS1.1 cells grown in monoculture and VA10 cells cultured in ALI conditions, with and without Azm treatment. Lipid extracts were analyzed with UPLC-MS. Ion chromatograms of Azm treated VA10 cells cultured in monolayer showed two large unidentified peaks at 2.99- and 3.66-min retention times that were not present in the untreated cells (Fig. 6a). Ion spectra of these peaks show that they contained fragment patterns similar to Azm but without the native form at $\mathrm{m} / \mathrm{z}=750$. Unknown compounds of $\mathrm{m} / \mathrm{z}=239$ (2.99 peak) and $\mathrm{m} / \mathrm{z}=$ 267 (3.66 peak) appear to be conjugated to Azm to create compounds of $\mathrm{m} / \mathrm{z}=988$ or $\mathrm{m} / \mathrm{z}=1016$, respectively (Fig. 6b). These charge-mass ratios correspond to 


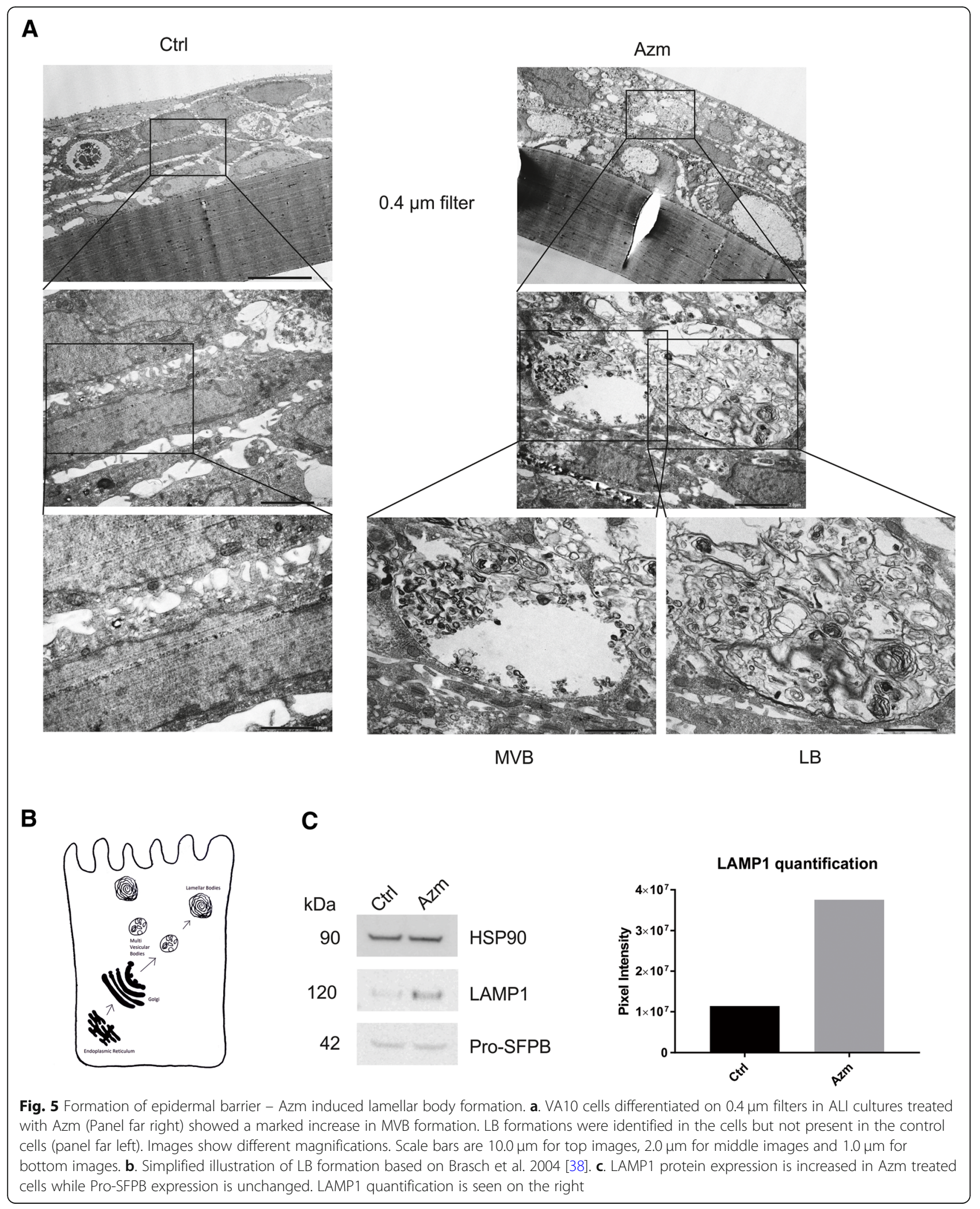


A

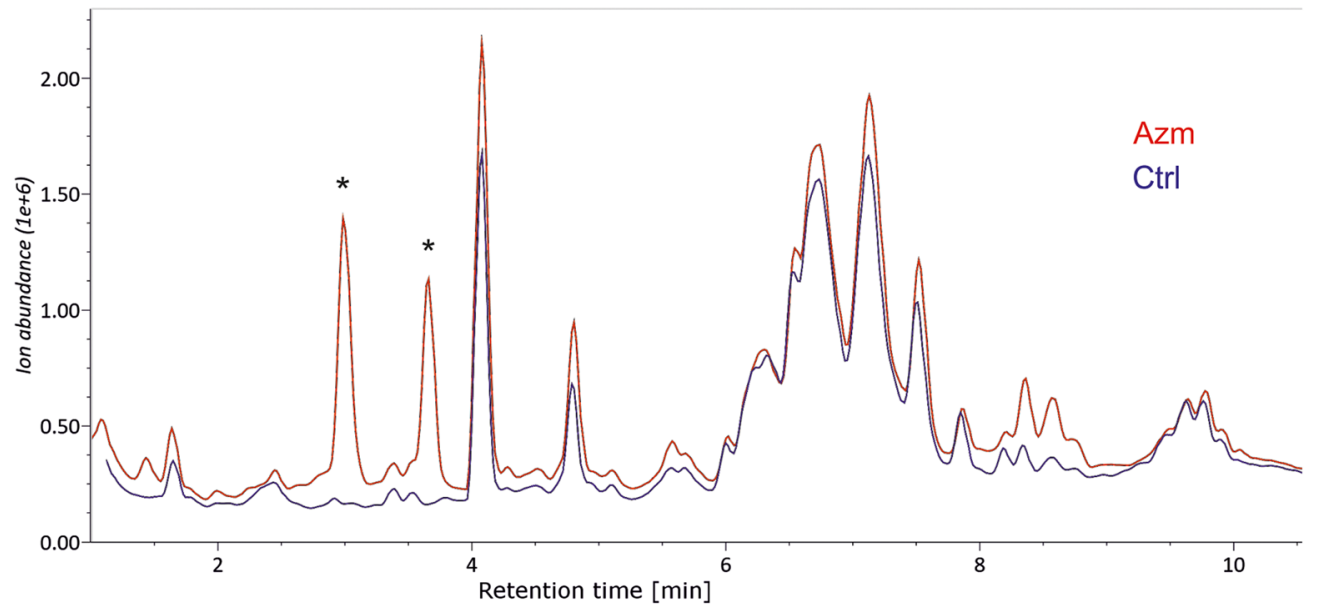

B

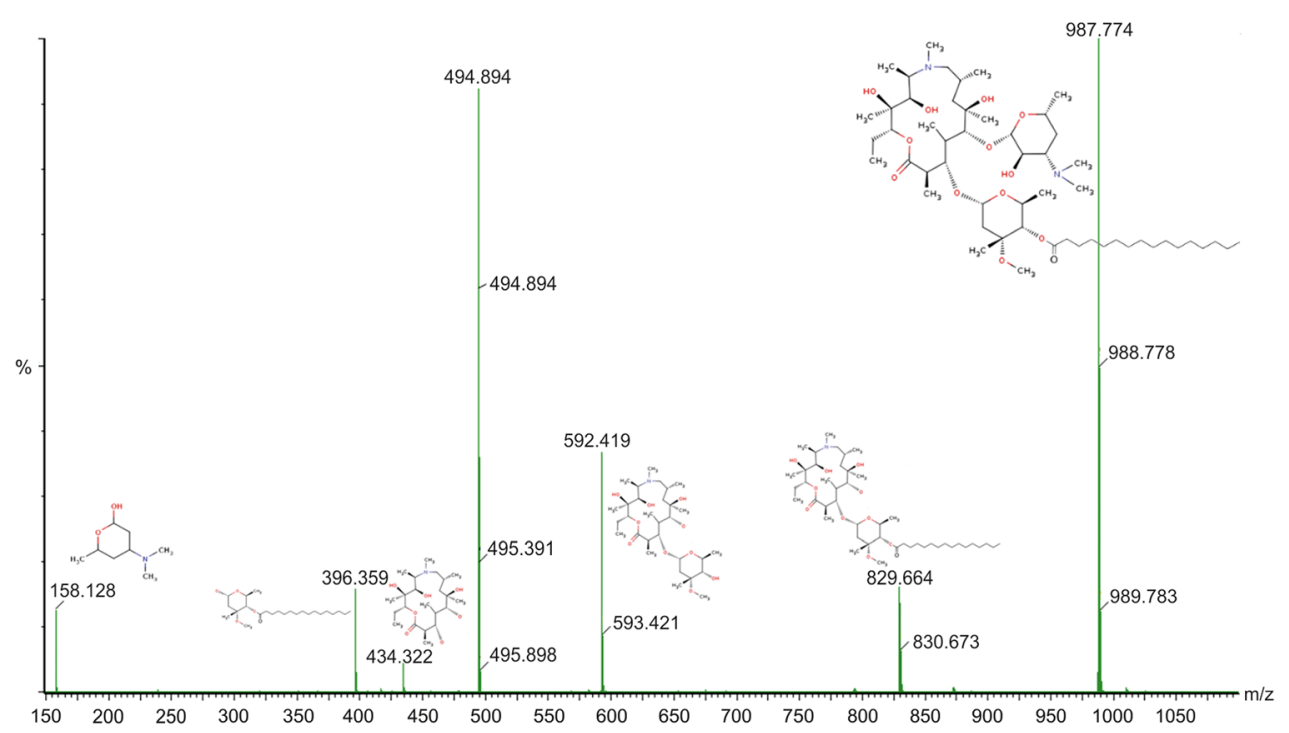

C

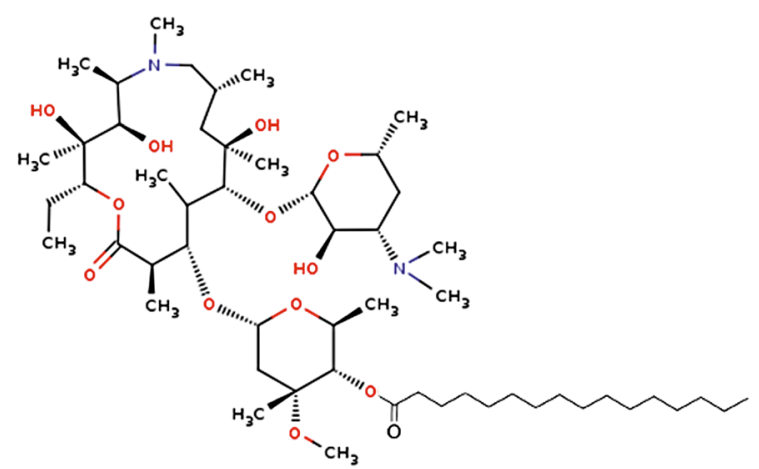

Fig. 6 (See legend on next page.) 
(See figure on previous page.)

Fig. 6 Conjugation of fatty acids to Azm in treated airway epithelia. a) Total ion chromatograms of representative samples of control (blue) and Azm treated VA10 cells (red). Large peaks appear at 2.99 and $3.66 \mathrm{~min}$ in the Azm treated cells. b) Fragmentation of these peaks (2.99 peak shown here) shows many similarities to the fragmentation pattern of Azm but with an $\mathrm{m} / \mathrm{z}$ shift of 239.3 in some of the fragments. This corresponds precisely to condensation of palmitate to one of the side-groups of $A Z M$ while releasing $\mathrm{H}_{2} \mathrm{O}$. A similar pattern, with a shift of $\mathrm{m} / \mathrm{z}=$ 267.3 was seen in the fragmentation of the 3.66 peak. This corresponds to condensation of stearate to Azm. c) Chemical structure of palmitate Azm conjugate

condensation of saturated fatty acids, specifically palmitate (C16:0) and stearate (C18:0) to Azm (Fig. 6c). A smaller peak representing Azm conjugation to myristic acid (C14:0) was also detected. Azm-lipid conjugates were detected in high quantities in both VA10 cells and BCi-NS1.1 cells treated with Azm. These Azm-lipid conjugates were also present in VA10 ALI cultures treated with Azm for 3 weeks, although these changes were not as pronounced.

Targeted analysis of 57 lipid species of six lipid classes showed accumulation of phosphatidylcholine (PC) species and lyso-phosphatidylcholine (lysoPC) in Azm treated ALI cultures, as well as ceramide derivatives (ceramide and sphingomyelin (SM)) (Fig. 7a). Figure 7b depicts a heatmap of all lipids identified in the analysis. In general, most of the PCs are higher in all the Azm treated samples than any of the control samples. The only exceptions are the long-chain poly-unsaturated PCs; PC 38:4 and PC 38:5 that are either not different between the two groups or higher in untreated cells. All lysoPCs analyzed here are more pronounced in the Azm treated cells than the untreated cells. In contrast, with the exception of PC-plasmalogen 34:0, the plasmalogens detected were found to be reduced in Azm treated cells compared to untreated cells. All SM species detected were more abundant in Azm treated cells as were most of the ceramide species. The only exception was ceramide 18:1/16:0 which was higher in the untreated cells. Of the 18 triacylglycerol (TAG) species, all but one were found at similar levels between Azm treated and control cells. The exception was TAG 54:5 that was found to be higher in the untreated cells. This was the TAG species with the highest level of unsaturation having five double-bonds.

Taken together, Azm appears to be conjugated to saturated fatty acids upon entering the cell. The direct functional consequences of this are unknown. During differentiation of the cells during ALI, Azm treated cells maintain far higher levels of structural phospholipids such as PC and SM while storage lipids such as TAG are unaffected.

\section{Discussion}

We have previously shown that Azm increases TEER in a bronchial-derived basal epithelial cell line, VA10, when cultured in ALI conditions [21]. Here, we show that
Azm induces an increase in TEER that corresponds to a decrease in paracellular flux, in both the VA10 and the bronchial-derived basal cell line BCi-NS1.1 [25].This suggests that Azm treatment of cultured airway epithelial cells results in increased integrity of an epithelial barrier in culture and enhanced barrier functions. Furthermore, we have demonstrated that Azm treatment alters the global gene expression pattern over time in airway epithelial ALI cultures. Ten days of Azm treatment results in increased lipid metabolism, which complements microarray study findings from Ribeiro et al. [40], who found that Azm treatment of human bronchial epithelial (HBE) cells resulted in upregulated lipid / cholesterol metabolism after $24 \mathrm{~h}$ of treatment. In the skin, lipid-rich lamellar bodies (LB) are first seen in the spinous layer, accumulate in the granular layer and finally form the intercellular lamella of the stratum corneum. The intercellular lamellae contain cholesterols, along with phospholipids and glucosylceramides, and together these lipids create a hydrophobic layer that is key in the permeability barrier of the skin [41]. Here, we have observed initial alterations associated with lipid remodeling and metabolism at day 10, with an increased expression pattern towards epidermal differentiation extending to day 22. Within the epidermal gene expression data set, subclasses such as desmosome-related genes, corneocyte lipid envelope and cornification, are highly enriched. Conceivably related to this epidermal phenotype shift, we found the formation of MVB and ultimately, LB. LB formation in the lungs has traditionally been associated with type 2 alveolar cells, but has recently been reported in bronchial epithelial cells [42]. Club cells also express surfactant proteins (A, B, C and D) [43]. In the lungs, LB derived from MVB are lipidprotein transporters, important in the transporting of surfactant proteins to the lumen of the alveoli and vital to epidermal barrier formation [38]. Pro-surfactant B (Pro-SFPB) is processed into its mature form from the Golgi complex via the MVB into LB, which in turn transport the surfactant to the cell membrane for excretion [38] (Fig. 5c). In the epidermis, LB are formed in the trans-Golgi network and their main function is to secrete and deliver lipids (mostly cholesterol, glucosylceramides, phospholipids and sphingomyelin) to the extracellular reaches of the stratum corneum, crucial for the integrity of the permeability/water barrier. The 
A

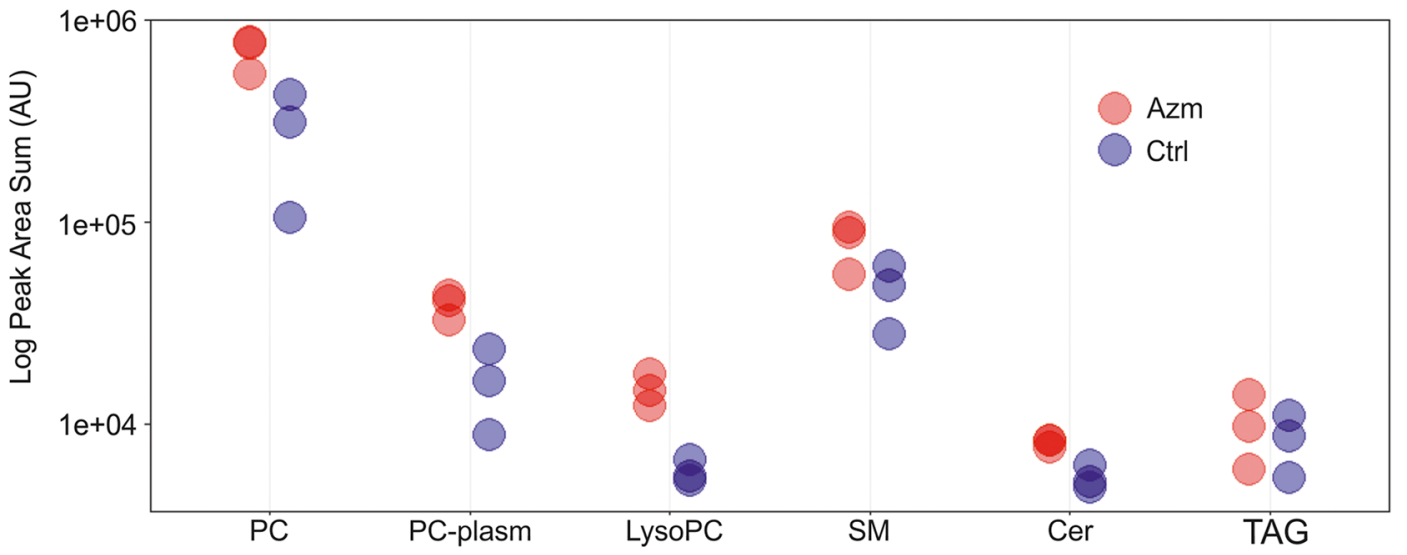

B

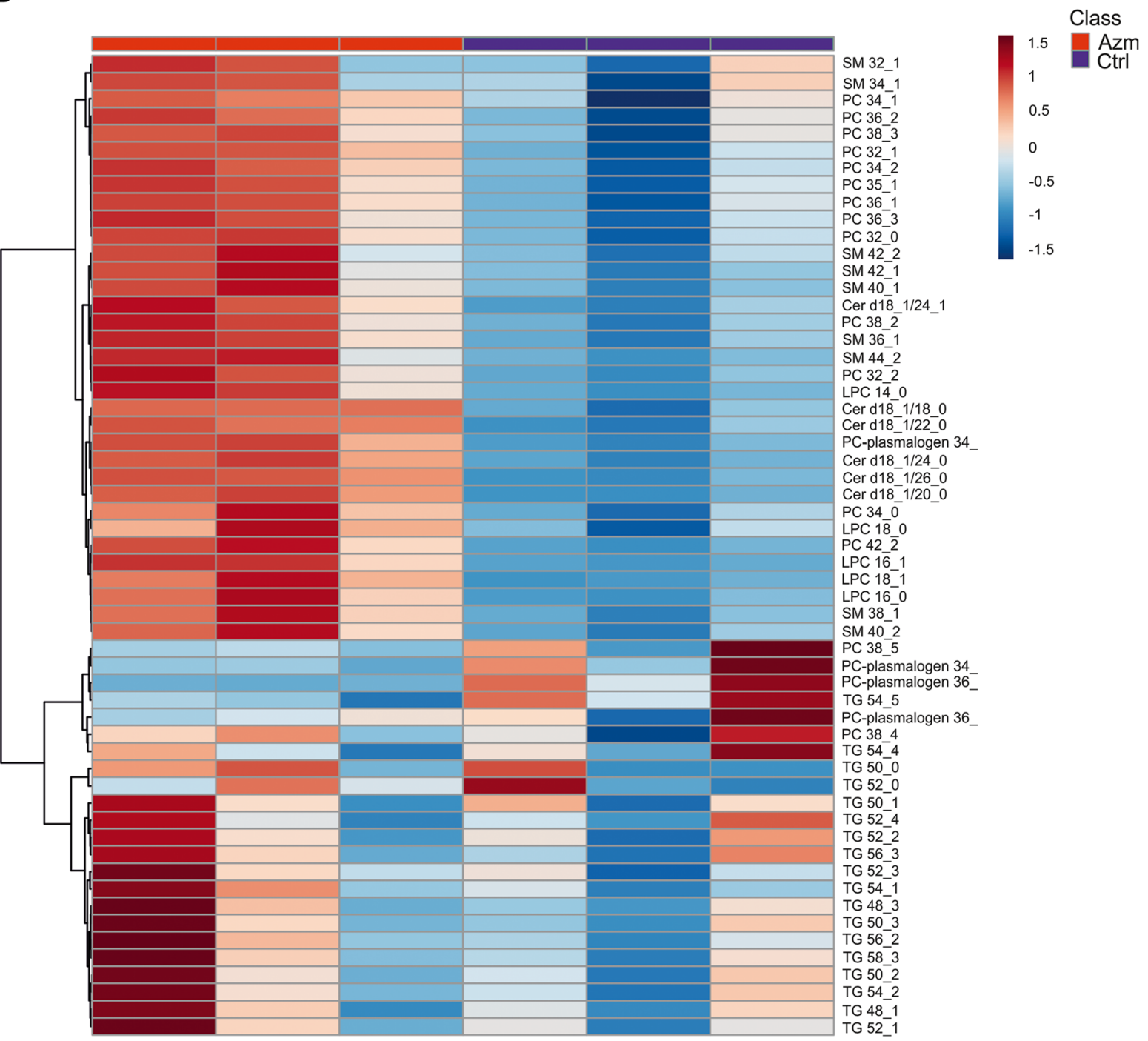

Fig. 7 Lipid composition of Azm treated airway epithelia during prolonged ALI culture. a) Relative abundance of 6 lipid classes in Azm treated (red) and untreated cells (blue). b) Heatmap of the 50 compounds that demonstrate the largest differences between Azm treated and untreated cells. Values were normalized by total lipid intensity 
finding that Azm induces the expression of various subclasses within epidermal differentiation in bronchial epithelial cells and enhances the epithelial barrier is of interest, not only for the respiratory epithelium but possibly for other epithelial layers as well. Increased TEER in ALI cultured lung cells and thus enhanced barrier effect has been explained by greater tight junction expression [21]. Our results indicate that a contributing factor to increased TEER could be lipid accumulation in cells, as fatty tissues are among the most resistant of human tissues [44].

The results presented here indicate that the induction of epidermal differentiation genes following treatment with Azm causes formation of MVB and LB. This is accompanied by thickening of the cell layer and sequestering of Azm-lipid conjugates into intracellular droplets that may partly be responsible for barrier enhancement. Azm is a cationic amphiphilic drug and as such is a known inducer of phospholipidosis [45]. In a recent article, Liu et al. argued that drug induced phospholipidosis, which has historically been viewed as an adverse side-effect of macrolide treatment, could be beneficial under certain circumstances [46]. These authors demonstrated that Azminduced phospholipidosis brought about accumulation of LB in human Meibomian gland epithelial cells promoting their function. We propose that Azm is having a similar effect in the airway epithelium. Azm has been shown to improve disease burden of patients with idiopathic pulmonary fibrosis [47] and CF, making it essential to better understand the mechanisms involved in order to discover and produce more specific and relevant pharmaceuticals aimed at patients with these debilitating diseases.

Azm has been of clinical interest due to its immunomodulatory properties and the reports of it leading to a reduction in chronic airway disease exacerbations. Attempts have been made to analyze alterations in gene expression of airway epithelium subsequent to low dose Azm treatment, mostly focusing on downregulated genes [48]. The targeted research for the immunomodulatory mechanism has dominated the field and other possible mechanisms have been largely neglected. We herein, report on the temporal involvement of lipid-cholesterol metabolism and cornification resulting in a strengthened epithelial barrier.

Azm displays beneficial effects in chronic airway disease patients, but as it is an antibiotic, extended clinical use of Azm has the potential to facilitate pathogen drug resistance. A more effective drug in the treatment of these patients would be a non-antibiotic derivative of Azm with anti-inflammatory and epithelial barrier enhancing effects. It is anticipated that our results will assist in the development of non-antibiotic derivatives of Azm to enhance epithelial barrier function as a novel approach to the treatment of respiratory diseases.

\section{Conclusions}

The data provided herein contribute to our understanding of the mode of action of Azm in the treatment of respiratory diseases and confirm that Azm is more than an anti-microbial drug. Via mechanisms involving lipid metabolism and upregulation of distinct ontologies of genes pertaining to epidermal differentiation, Azm strengthens epithelial airway barriers. The barrier enhancing effects of Azm in vitro are likely a consequence of a combination of events that occur during long term treatment and which results in multiple intracellular changes, which require deeper investigation.

\section{Additional files}

Additional file 1: Figure S1. Azm treatment of BCi-NS1.1 cells leads to increased vesicle formation Transmission electron microscope images show that BCi-NS1.1 cells treated with Azm have substantially more vesicle formation than the untreated controls. Left scale bars are $10.0 \mu \mathrm{m}$ and right scale bars are $1.0 \mu \mathrm{m}$. (TIF $18391 \mathrm{~kb}$ )

Additional file 2: Figure S2. Azm induced MVB and LB formation. A) BCi-NS1.1 cells differentiated in ALI cultures treated with Azm showed a marked increase in MVB and LB formations. Shown are two different cross sectional TEM images of transwell filters. Scale bars are from left 10.0, 2.0, 1.0 and $1.0 \mu \mathrm{m}$. B) Treating differentiated VA10 cells with a clinical formulation of Azm (Zithromax) also resulted in increased MVB and LB formations. Top scale bars are $5.0 \mu \mathrm{m}$ and bottom scale bars are $1.0 \mu \mathrm{m} . \mathrm{C}$ ) Differentiated BCi-NS1.1 cells showed similar MVB and LB formations after treatment with Azm (Zithromax). Top scale bars are $5.0 \mu \mathrm{m}$ and bottom scale bars are $1.0 \mu \mathrm{m}$. (TIF $33306 \mathrm{~kb}$ )

\begin{abstract}
Abbreviations
ACN: acetonitrile; ALI: air-liquid interface; Azm: azithromycin; CF: cystic fibrosis; EDC: epidermal differentiation complex; GO: gene ontology; HBE: human bronchial epithelial; HBSS: Hanks' balanced salt solution; LB: lamellar bodies; MMP: metalloprotease; MVB: multivesicular bodies; PC: phosphatidylcholine; SAG: skin associated genes; SFPB: surfactant protein B; SM: sphingomyelin; TAG: triacylglycerol; TEER: transepithelial electrical resistance
\end{abstract}

\section{Acknowledgements}

We thank Páll Melsted (School of Engineering and Natural Sciences, University of Iceland) for his assistance with the sequencing analysis.

\section{Ethics approval and consent}

Not applicable.

\section{Authors' contributions}

AJA, JPJ and JAK designed, performed, and analyzed experiments and wrote the manuscript. BV performed ALI and RT-qPCR experiments. SI performed confocal imaging. Both BV and SI were involved in experimental design. SS and AG analyzed RNA Seq data. SH, FJ and OR performed and analyzed lipid data experiments. PC performed sample preparation and transmission electron microscopy. FL, FRG, GHG, CPP, OB and TG were involved in design of the experiments and interpretation of the data. TG and JAK supervised the study. All authors read and approved the final manuscript.

\section{Funding}

This work was supported by the Icelandic Research Council Technical Fund (Rannís Grant numbers: 142264-0611; 163757), and EpiEndo Pharmaceuticals, Reykjavik, Iceland.

\section{Availability of data and materials}

RNA sequencing data with accession number GSE128523 will be publicly available at GEO. Other data are included within this manuscript. 


\section{Consent for publication}

All authors read the manuscript and gave their consent for publication.

\section{Competing interests}

The authors have declared that some of the authors work for and / or are shareholders in EpiEndo Pharmaceuticals (AJA, BV, FL, SI, GHG, FRG, CPP, OB, $\mathrm{TG}, \mathrm{JK})$.

\section{Author details}

${ }^{1}$ Stem Cell Research Unit, BioMedical Center, School of Health Sciences, University of Iceland, Reykjavík, Iceland. ${ }^{2}$ Center for Systems Biology, University of Iceland, Reykjavík, Iceland. ${ }^{3}$ Department of Laboratory Hematology, Landspitali-University Hospital, Iceland, Reykjavík, Iceland. ${ }^{4}$ Department of Anatomy, Faculty of Medicine, University of Iceland, Reykjavík, Iceland. ${ }^{5}$ BioMedical Center, Life and Environmental Sciences, University of Iceland, Reykjavík, Iceland. 'EpiEndo Pharmaceuticals, Reykjavík, Iceland. 'Department of Respiratory Medicine, Landspitali-University Hospital, Reykjavík, Iceland. ${ }^{8}$ Sackler Institute of Pulmonary Pharmacology, Institute of Pharmaceutical Science, King's College London, London, UK.

\section{Received: 4 April 2019 Accepted: 14 June 2019}

Published online: 24 June 2019

\section{References}

1. Halpin DM, Miravitlles M, Metzdorf N, Celli B. Impact and prevention of severe exacerbations of COPD: a review of the evidence. Int J Chron Obstruct Pulmon Dis. 2017;12:2891-908. https://doi.org/10.2147/copd.S139470.

2. Albert RK, Connett J, Bailey WC, Casaburi R, Cooper JA Jr, Criner GJ, Curtis $J$, Dransfield MT, Han MK, Lazarus SC, et al. Azithromycin for prevention of exacerbations of COPD. N Engl J Med. 2011;365:689-98. https://doi.org/10. 1056/NEJMoa1104623.

3. Koyama H, Geddes DM. Erythromycin and diffuse panbronchiolitis. Thorax. 1997:52:915-8

4. Parnham MJ, Erakovic Haber V, Giamarellos-Bourboulis EJ, Perletti G, Verleden GM, Vos R. Azithromycin: mechanisms of action and their relevance for clinical applications. Pharmacol Ther. 2014;143:225-45. https:// doi.org/10.1016/j.pharmthera.2014.03.003.

5. Principi N, Blasi F, Esposito S. Azithromycin use in patients with cystic fibrosis. Eur J Clin Microbiol Infect Dis. 2015;34:1071-9. https://doi.org/10. 1007/s10096-015-2347-4.

6. Ramos FL, Criner GJ. Use of long-term macrolide therapy in chronic obstructive pulmonary disease. Curr Opin Pulm Med. 2014;20:153-8. https:// doi.org/10.1097/mcp.0000000000000028.

7. Taylor SP, Sellers E, Taylor BT. Azithromycin for the prevention of COPD exacerbations: the good, bad, and ugly. Am J Med. 2015;128:1362.e1361-6. https://doi.org/10.1016/j.amjmed.2015.07.032.

8. Wong C, Jayaram L, Karalus N, Eaton T, Tong C, Hockey H, Milne D, Fergusson W, Tuffery C, Sexton P, et al. Azithromycin for prevention of exacerbations in non-cystic fibrosis bronchiectasis (EMBRACE): a randomised, double-blind, placebo-controlled trial. Lancet. 2012;380:660-7. https://doi.org/10.1016/s0140-6736(12)60953-2.

9. Cramer CL, Patterson A, Alchakaki A, Soubani AO. Immunomodulatory indications of azithromycin in respiratory disease: a concise review for the clinician. Postgrad Med. 2017;129:493-9. https://doi.org/10.1080/00325481.2017.1285677.

10. Naderi N, Assayag D, Mostafavi-Pour-Manshadi SM, Kaddaha Z, Joubert A, Ouellet I, Drouin I, Li PZ, Bourbeau J. Long-term azithromycin therapy to reduce acute exacerbations in patients with severe chronic obstructive pulmonary disease. Respir Med. 2018;138:129-36. https://doi.org/10.1016/j. rmed.2018.03.035.

11. Pomares X, Monton C, Espasa M, Casabon J, Monso E, Gallego M. Long-term azithromycin therapy in patients with severe COPD and repeated exacerbations. Int J Chron Obstruct Pulmon Dis. 2011;6:449-56. https://doi.org/10.2147/copd.S23655.

12. Kudoh S, Azuma A, Yamamoto M, Izumi T, Ando M. Improvement of survival in patients with diffuse panbronchiolitis treated with low-dose erythromycin. Am J Respir Crit Care Med. 1998;157:1829-32. https://doi.org/ 10.1164/ajrccm.157.6.9710075.

13. Pomares X, Monton C, Bullich M, Cuevas O, Oliva JC, Gallego M, Monso E. Clinical and safety outcomes of long-term azithromycin therapy in severe COPD beyond the first year of treatment. Chest. 2018;153:1125-33. https:// doi.org/10.1016/j.chest.2018.01.044.
14. Uzun S, Djamin RS, Kluytmans JA, Mulder PG, van't Veer NE, Ermens AA, Pelle AJ, Hoogsteden HC, Aerts JG, van der Eerden MM. Azithromycin maintenance treatment in patients with frequent exacerbations of chronic obstructive pulmonary disease (COLUMBUS): a randomised, double-blind, placebo-controlled trial. Lancet Respir Med. 2014;2:361-8. https://doi.org/10. 1016/s2213-2600(14)70019-0.

15. Washington JA 2nd, Wilson WR. Erythromycin: a microbial and clinical perspective after 30 years of clinical use (1). Mayo Clin Proc. 1985;60:189-203.

16. Washington JA, 2nd, Wilson WR: Erythromycin: a microbial and clinical perspective after 30 years of clinical use (2). Mayo Clin Proc 1985, 60:271-278.

17. Retsema J, Girard A, Schelkly W, Manousos M, Anderson M, Bright G, Borovoy R, Brennan L, Mason R. Spectrum and mode of action of azithromycin (CP62,993), a new 15-membered-ring macrolide with improved potency against gram-negative organisms. Antimicrob Agents Chemother. 1987;31:1939-47.

18. Durkin MJ, Jafarzadeh SR, Hsueh K, Sallah YH, Munshi KD, Henderson RR, Fraser VJ. Outpatient antibiotic prescription trends in the United States: a National Cohort Study. Infect Control Hosp Epidemiol. 2018;39:584-9. https://doi.org/10.1017/ice.2018.26.

19. Kanoh S, Rubin BK. Mechanisms of action and clinical application of macrolides as immunomodulatory medications. Clin Microbiol Rev. 2010;23: 590-615. https://doi.org/10.1128/cmr.00078-09.

20. Gibson PG, Yang IA, Upham JW, Reynolds PN, Hodge $S$, James AL, Jenkins $C$, Peters MJ, Marks GB, Baraket M, et al. Effect of azithromycin on asthma exacerbations and quality of life in adults with persistent uncontrolled asthma (AMAZES): a randomised, double-blind, placebo-controlled trial. Lancet. 2017;390:659-68. https://doi.org/10.1016/s0140-6736(17)31281-3.

21. Asgrimsson V, Gudjonsson T, Gudmundsson GH, Baldursson O. Novel effects of azithromycin on tight junction proteins in human airway epithelia. Antimicrob Agents Chemother. 2006;50:1805-12. https://doi.org/10.1128/ aac.50.5.1805-1812.2006.

22. Halldorsson S, Gudjonsson T, Gottfredsson M, Singh PK, Gudmundsson GH, Baldursson O. Azithromycin maintains airway epithelial integrity during Pseudomonas aeruginosa infection. Am J Respir Cell Mol Biol. 2010;42:62-8. https://doi.org/10.1165/rcmb.2008-03570C.

23. Slater M, Torr E, Harrison T, Forrester D, Knox A, Shaw D, Sayers I. The differential effects of azithromycin on the airway epithelium in vitro and in vivo. Physiol Rep. 2016;4. https://doi.org/10.14814/phy2.12960.

24. Halldorsson S, Asgrimsson V, Axelsson I, Gudmundsson GH, Steinarsdottir M, Baldursson O, Gudjonsson T. Differentiation potential of a basal epithelial cell line established from human bronchial explant. In Vitro Cell Dev Biol Anim. 2007;43:283-9. https://doi.org/10.1007/s11626-007-9050-4.

25. Walters MS, Gomi K, Ashbridge B, Moore MA, Arbelaez V, Heldrich J, Ding BS, Rafii S, Staudt MR, Crystal RG. Generation of a human airway epithelium derived basal cell line with multipotent differentiation capacity. Respir Res. 2013;14:135. https://doi.org/10.1186/1465-9921-14-135.

26. Bray NL, Pimentel H, Melsted P, Pachter L. Near-optimal probabilistic RNA-seq quantification. Nat Biotechnol. 2016;34:525-7. https://doi.org/10.1038/nbt.3519.

27. Pimentel H, Bray NL, Puente S, Melsted P, Pachter L. Differential analysis of RNA-seq incorporating quantification uncertainty. Nat Methods. 2017;14: 687-90. https://doi.org/10.1038/nmeth.4324.

28. Mi H, Muruganujan A, Casagrande JT, Thomas PD. Large-scale gene function analysis with the PANTHER classification system. Nat Protoc. 2013;8: 1551-66. https://doi.org/10.1038/nprot.2013.092.

29. Chong J, Soufan O, Li C, Caraus I, Li S, Bourque G, Wishart DS, Xia J. MetaboAnalyst 4.0: towards more transparent and integrative metabolomics analysis. Nucleic Acids Res. 2018;46:W486-w494. https://doi.org/10.1093/nar/gky310.

30. Arason AJ, Jonsdottir HR, Halldorsson S, Benediktsdottir BE, Bergthorsson JT, Ingthorsson S, Baldursson O, Sinha S, Gudjonsson T, Magnusson MK. deltaNp63 has a role in maintaining epithelial integrity in airway epithelium. PLoS One. 2014;9:e88683. https://doi.org/10.1371/journal.pone.0088683.

31. Ni W, Shao X, Cai X, Wei C, Cui J, Wang R, Liu Y. Prophylactic use of macrolide antibiotics for the prevention of chronic obstructive pulmonary disease exacerbation: a meta-analysis. PLoS One. 2015;10:e0121257. https:// doi.org/10.1371/journal.pone.0121257.

32. Mi H, Huang X, Muruganujan A, Tang H, Mills C, Kang D, Thomas PD. PANTHER version 11: expanded annotation data from gene ontology and Reactome pathways, and data analysis tool enhancements. Nucleic Acids Res. 2017:45:D183-d189. https://doi.org/10.1093/nar/gkw1138.

33. Jungersted JM, Hellgren LI, Jemec GB, Agner T. Lipids and skin barrier function--a clinical perspective. Contact Dermatitis. 2008;58:255-62. https:// doi.org/10.1111/j.1600-0536.2008.01320.x. 
34. Segre JA. Epidermal barrier formation and recovery in skin disorders. J Clin Invest. 2006;116:1150-8. https://doi.org/10.1172/jci28521.

35. Wikramanayake TC, Stojadinovic O, Tomic-Canic M. Epidermal differentiation in barrier maintenance and wound healing. Adv Wound Care (New Rochelle). 2014;3:272-80. https://doi.org/10.1089/wound.2013.0503.

36. Gon Y, Maruoka S, Kishi H, Kozu Y, Kazumichi K, Nomura Y, Takeshita I, Oshima T, Hashimoto S. NDRG1 is important to maintain the integrity of airway epithelial barrier through claudin-9 expression. Cell Biol Int. 2017;41: 716-25. https://doi.org/10.1002/cbin.10741.

37. Gerber PA, Hevezi P, Buhren BA, Martinez C, Schrumpf H, Gasis M, GretherBeck S, Krutmann J, Homey B, Zlotnik A. Systematic identification and characterization of novel human skin-associated genes encoding membrane and secreted proteins. PLoS One. 2013;8:e63949. https://doi.org/ 10.1371/journal.pone.0063949.

38. Brasch F, Johnen G, Winn-Brasch A, Guttentag SH, Schmiedl A, Kapp N, Suzuki Y, Muller KM, Richter J, Hawgood S, Ochs M. Surfactant protein B in type II pneumocytes and intra-alveolar surfactant forms of human lungs. Am J Respir Cell Mol Biol. 2004;30:449-58. https://doi.org/10.1165/rcmb.2003-0262OC.

39. Oosterlaken-Dijksterhuis MA, van Eijk M, van Buel BL, van Golde LM, Haagsman HP. Surfactant protein composition of lamellar bodies isolated from rat lung. Biochem J. 1991;274 ( Pt 1:115-9.

40. Ribeiro CM, Hurd H, Wu Y, Martino ME, Jones L, Brighton B, Boucher RC, O'Neal WK. Azithromycin treatment alters gene expression in inflammatory, lipid metabolism, and cell cycle pathways in well-differentiated human airway epithelia. PLoS One. 2009;4:e5806. https://doi.org/10.1371/journal.pone.0005806.

41. van Smeden J, Bouwstra JA. Stratum Corneum lipids: their role for the skin barrier function in healthy subjects and atopic dermatitis patients. Curr Probl Dermatol. 2016;49:8-26. https://doi.org/10.1159/000441540.

42. Fukumoto J, Soundararajan R, Leung J, Cox R, Mahendrasah S, Muthavarapu $\mathrm{N}$, Herrin T, Czachor A, Tan LC, Hosseinian N, et al. The role of club cell phenoconversion and migration in idiopathic pulmonary fibrosis. Aging (Albany NY). 2016;8:3091-109. https://doi.org/10.18632/aging.101115.

43. Boggaram V. Regulation of lung surfactant protein gene expression. Front Biosci. 2003;8:d751-64.

44. Faes TJ, van der Meij HA, de Munck JC, Heethaar RM. The electric resistivity of human tissues (100 Hz-10 MHz): a meta-analysis of review studies. Physiol Meas. 1999:20:R1-10.

45. Shayman JA, Abe A. Drug induced phospholipidosis: an acquired lysosomal storage disorder. Biochim Biophys Acta. 2013;1831:602-11. https://doi.org/ 10.1016/j.bbalip.2012.08.013.

46. Liu Y, Kam WR, Ding J, Sullivan DA. One man's poison is another man's meat: using azithromycin-induced phospholipidosis to promote ocular surface health. Toxicology. 2014;320:1-5. https://doi.org/10.1016/.jtox.2014.02.014

47. Kawamura K, Ichikado K, Yasuda Y, Anan K, Suga M. Azithromycin for idiopathic acute exacerbation of idiopathic pulmonary fibrosis: a retrospective single-center study. BMC Pulm Med. 2017;17:94. https://doi. org/10.1186/s12890-017-0437-z.

48. Baines KJ, Wright TK, Gibson PG, Powell H, Hansbro PM, Simpson JL. Azithromycin treatment modifies airway and blood gene expression networks in neutrophilic COPD. ERJ Open Res. 2018:4. https://doi.org/10. 1183/23120541.00031-2018

\section{Publisher's Note}

Springer Nature remains neutral with regard to jurisdictional claims in published maps and institutional affiliations.

Ready to submit your research? Choose BMC and benefit from:

- fast, convenient online submission

- thorough peer review by experienced researchers in your field

- rapid publication on acceptance

- support for research data, including large and complex data types

- gold Open Access which fosters wider collaboration and increased citations

- maximum visibility for your research: over $100 \mathrm{M}$ website views per year

At BMC, research is always in progress.

Learn more biomedcentral.com/submissions 